\title{
Load Bearing Strength of Innovative I-Shapes of Cold Formed Steel Sections
}

\author{
Lokendra Kaushal ${ }^{1}$, Mohd Rashid ${ }^{2}$ \\ ${ }^{1}$ Department of Civil Engineering, Future Institute of Engineering \& Technology, Bareilly, India \\ ${ }^{2}$ Department of Civil Engineering, Rajshree Institute of Engineering \& Technology, Bareilly, India
}

Email address:

lokendrakaushal.21@gmail.com (L. Kaushal),mohd13728@gmail.com (M. Rashid)

\section{To cite this article:}

Lokendra Kaushal, Mohd Rashid. Load Bearing Strength of Innovative I-Shapes of Cold Formed Steel Sections. International Journal of Industrial and Manufacturing Systems Engineering. Vol. 4, No. 4, 2019, pp. 31-40. doi: 10.11648/j.ijimse.20190404.11

Received: October 2, 2019; Accepted: October 18, 2019; Published: October 25, 2019

\begin{abstract}
In recent years, cold formed steel sections are used more and more as primary framing components as well as secondary structural systems. The geometry can significantly influence the stability response of cold formed steel members. This reportis an investigation concerning the structural behavior of the cold formed steel beams and their failure modes. The beam profile is cold formed steel section and experimental procedure on cold formed steel section is conducted. Thin sheet steel products are extensively used in building industry, and range from purlins to roof sheeting and floor decking. Generally, these are available for use as basic building elements for assembly at site or as prefabricated frames or panels. These thin steel sections are cold-formed, i.e. their manufacturing process involves forming steel sections in a cold state (i.e. without application of heat) from steel sheets of uniform thickness. Sometimes they are also called Light Gauge Steel Sections or Cold Rolled Steel Sections. The thickness of steel sheet used in cold formed section construction was $3.1 \mathrm{~mm}$. The method of manufacturing is important as it differentiates these products from hot rolled steel sections. Normally, the yield strength of steel sheets used in cold-formed sections is at least $280 \mathrm{~N} / \mathrm{mm}^{2}$, although there is a trend to use steels of higher strengths, and sometimes as low as $230 \mathrm{~N} / \mathrm{mm}^{2}$.
\end{abstract}

Keywords: Load Bearing Strength, Cold Formed Steel Sheets, Innovative I-section, UTM Machine, Pressing Machine

\section{Introduction}

In steel structures, two essential basic steel part sorts are utilized:

1) Cold rolled steel members.

2) Hot rolled steel members.

The Hot rolled steel members are framed at raised temperature though Cold shaped steel are framed at room temperature. The Hot rolled segment are overwhelming weight rather than this; Cold framed steel is less weight. Cross sectional shapes are framed to close resilience and these can be reliably rehashed for whatever length of time that required.

Cold rolled section can be utilized to create any coveted shape to any coveted length. It is believable to demolish the material from neutral axis to upgrade the load carrying capacity.

Cold formed steel segments are broadly utilized in construction and building enterprises. The prevalence of these items has drastically expanded as of late because of their extensive variety of utilization, simplicity of manufacture and high quality to-weight proportions. Cold formed steel members are either cold rolled or brakesqueezed into basic shapes.

\section{Objective}

The main objective of this research work is to determine the following parameters.

1) To study the maximum compressive strength of different innovative I shaped cold formed steel sections.

2) To study bending behavior of cold formed steel beam sections.

3) To study buckling behavior of cold formed steel beam sections.

4) To calculate the load carrying capacity of different cold formed steel beam sections. 


\section{Methodology}

We used the following procedures for carrying out our research work.

1) First of all, I have read my previous article published related to my work. Then I decided my exact title of research work.

2) We have decided to work on that area which is not considered yet.

3) We take a standard I - Section (beam), calculate the maximum load carrying of that I - Section.

4) Decided the various shapes of innovative I shaped cold formed beam sections.

5) Designing of different innovative I shaped cold formed beam sections, one by one.

6) Manufacturing of different innovative I shaped cold formed beam sections, in the cold formed beam workshop with the help of workshop staff \& classmates.

7) During the manufacturing of different innovative I shaped cold formed beam sections, dimensions \& angle of folding will be match with the design criteria.

8) Bring all the manufactured different innovative I shaped cold formed beam sections for Testing in Laboratory.

9) Testing of all the manufactured different innovative I shaped cold formed beam sections with the help of Universal Testing Machine in College Laboratory.

10)Record all the reading of different dial gauges as set before the testing of section.

11)Take a print out of all the recorded reading separately for each section.

12)Compare the result of all the sections \& find the section having the maximum load carrying capacity.

13)Draw the graph \& load deflection curve as recorded for all the sections.

\section{Literature Review}

There are following research papers which discuss about literature review.

Santaputra et al. (2015) [1]: Concentrated the web devastating conduct of high-quality frosty framed steel pillars. The creator explored diagnostically and tentatively both the cap areas and I-bars that were framed from five unique sorts of high-quality sheet steels. These were researched under different stacking conditions. The assessment demonstrates that the present accessible plan criteria were not reasonable for high quality materials with yield qualities surpassing $552 \mathrm{MPa}$. Consequently, new outline equations had been inferred for various sorts of stacking conditions with differing yield qualities going from 207 to $1,138 \mathrm{MPa}$. These conditions recognized web devastating disappointment brought about by overemphasizing and web clasping disappointment. The recently proposed plan conditions had been checked by test outcomes.
Jayaraman et al. (2014) [2]: Studied the conduct and efficient of cold shaped steel developed channel segment and channel segment by same cross sectional zone. General two examples were planned and examination of all the interior constrain, and thus, to assess the existing together minutes and shear powers at the basic cross-segment with same arrangement range by keeping every single other parameter steady. The primary point of the review gives which area is efficient, high bowing quality, more load conveying limit and high flexural quality by examination of hypothetical and numerical examination. In this way, channel area is most reasonable and prudent look at than the developed channel segment.

Divahar and Joanna (2014) [3]: Examined the aftereffects of the trial contemplate on the sidelong clasping conduct of frosty framed steel area with trapezoid web. A sum of six chilly framed steel pillars with plain networks and folded networks were tried. The minute conveying limit of cool framed steel pillar with plain web was examined and contrasted and the minute conveying limit of bar with trapezoidal creased web having 300 and 450 grooves. The examples were tried under two-point stacking for its immaculate flexural conduct. It was found that the cool framed steel bar with trapezoidal ridged web area have higher imperviousness to horizontal clasping contrasted with that of segment with plain web. Thus, it was presumed that the normal load conveying limit of frosty framed steel bars with 300 creased networks expanded by $25 \%$ than the shaft with plain web. Be that as it may, there was a lone minimal increment in load conveying of bar with 300 ridged networks than that of shaft with 450 creased networks.

Sudha. K and Sukumar (2014) [4]: An exploratory and numerical examination on the twisting quality and conduct of cold formed steel developed flexural individuals was contemplated. Eight examples with equivalent spines and with unequal ribs had been manufactured and tested. The exploratory outcomes demonstrated the methods of clasping and their impact on the bowing quality and conduct of icy framed developed I areas. At that point, the test results were confirmed by reproducing limited component models investigated utilizing FEM programming ANSYS. The outcomes acquired are in great concurrence with the trial comes about.

Gillbert H. Begain (2009) [5]: Light gauge frosty shaped steel profile: for decks in lodging units the sheet metal can furnish segment with the cool framed steel. To meet the different need of the development of staying at aggressive costs. another sort of channel profiles has been produced and connected for building the deck of a family house this channel profile space for warming ventilating and electrical conductors outlining inventive steel light gauge part thought inventiveness about the fashioner. the light weight brings channels, about acoustics however it diminishes the heap on the establishment.

PanagiotsFrantzis (2008) [6]: Sturdiness of cool shape steel: Joints are subjected to different consistent loads within the sight of room temperature. A graphite gage method is 
produced to screen the hatching for the ideal opportunity for a split to shape and measure its consequent velo. Is connected disappointment vitality. Two strategies are utilized first is testing ring and other is end projection arrangement was weak in nature contrasted with the model not surpass 40 $\mathrm{J} / \mathrm{m}^{2}$.

Cheng Yu and Benjamin W. Schafer (2006) [7]: Concentrated the distortional Buckling Tests on Cold-Formed Steel Beams. For frosty shaped steel joists, purlins, or girts, when the pressure rib has not been limited in connection to sheathing or framing, then distortional clasping be the vital disappointment mode. In this manner, a progression of distortional clasping tests on icy framed steel $\mathrm{C}$ and $\mathrm{Z}$ segments in bowing was directed. They were chosen to permit distortional clasping mode yet confine parallel torsional clasping. It was watched that expansive quality decreases are in the tried examples when distortional clasping started the disappointment rather than neighborhood clasping. Thus, the Australian/New Zealand Standard and the immediate quality technique gave express strategies to computing the limit in the distortional clasping mode.

Abbas et al (2006) [8]: Theoretically exhibited the Behavior of Corrugated Web I-Girders under In-Plane stacking condition. The balance of a length of a layered web I-brace was examined, and the cross-sectional burdens and stress resultants because of essential twisting minute and shear were reasoned. The examination demonstrated that a ridged web I-support will turn out-of-plane at the same time and redirected in-plane under the activity of in-plane burdens. In this paper, the in-plane bowing conduct was investigated utilizing traditional shaft hypothesis technique and the out-of-plane torsional conduct was breaking down as a spine transverse twisting issue. At last, limited component examination results were introduced and contrasted with the hypothetical outcomes for approval.

Juile Mill (2004) [9]: Self penetrating screw joint for cold frame steel channel entry: This paper is having $r / f$ the finish of prior testing by the main creator that broadly utilized shot and plate minutes' association is not appropriate. Joined segments having a lower outline limit than the Australian segment however this does not imply that similar issues with the regular joints won't happen only that they may happen in sheds of marginally lesser measurement in the assembled states than in Australian and henceforth the proposed selfboring screw joints are a legitimate alternative to defeat this issue in both nations For utilized as a part of the new joint of entrance edges built frame thin cold shaped channel area The other generally utilized joint arrangement of a mitered joint with two fasteners is end plates may should be estimated conservatively.

Nabil Abdel-Rahman and Sivakumaran (1997) [10]: Announced the aftereffects of trial examinations completed to assess the mechanical properties and the inherent remaining worries of chilly shaped steel segments. The examinations were performed on channel molded frosty framed steel areas fabricated utilizing icy roll shaping procedure. Pliable coupon tests were directed to assess the mechanical properties of areas. Electrical strain gages, were utilized to build up the sizes and the circulations of leftover burdens. Considering the trial comes about, investigation models for the anxiety strain relationship, the variety of the yield quality and the remaining worries in chilly framed steel channel segments have been built up. The proposed investigation models for material properties have been joined inside a vast miss happening shell limited component to shape an examination demonstrate for icy framed steel areas. The proficiency and precision of the proposed models and their material properties have been assessed by contrasting the limited component investigation comes about and the relating trial consequences of cool framed steel segments subjected to hub compressive burdens.

C. C Weng (1984) [11]: Pressure test on frosty frame steel segment: The flexural clasping quality of area is discovering first. The anxiety connection and shaping or press break operation used to shape the segment short segment the test is to do diminished corresponding points of confinement and great plans and sizes of the segments utilizing formulae IS 801. The outcome demonstrates the issues. contrast the hypothetical qualities and test values prove. In that time, we 93 columns look at it they are discover compressive quality along 68 columns, 25 short sections of column utilizing stress strain relationship and framing all operations.

\section{Experimental Setup}

\subsection{Introduction}

This chapter deals with the material \&experimental set up work which includes the following tests:

1) To study the behavior in the shape of innovative Isection with increase in the load.

2) Determine the load bearing capacity of innovative Ishapes.

3) Flexural bending strength of the innovative I-shapes.

\subsection{Materials Required}

To conduct load bearing strength of innovative I-shapes of cold formed steel sections following materials is required in the laboratory:

1) Cold formed steel sheets.

2) Sheet cutter machine.

3) Press-breaking machine.

4) Hammer.

5) Welding machine.

\subsubsection{Cold Formed Steel Sheets}

1) For the preparation of various innovative shapes of Isection I used a sheet of dimension 4' $\times 6$ '.

2) The thickness of the sheet is $3.15 \mathrm{~mm}$.

3) The test was carried out according to IS 800: 2007.

\subsubsection{Sheet Cutter Machine}

1) It is an electric machine which contains a hard iron blade with zig-zag edge. 
2) It rotates at very high speed and cuts the cold formed iron sheets.

\subsubsection{Press Breaking Machine}

1) It is the equipment which is used to mold forms the plane sheets in the desired shape.

2) It contains V-shaped grooves with male and female parts in between those grooves the sheet is placed on the right place to be bent and then it is pressed.

3 ) It is pressed in a controlled environment as pressing more than the desired may lead to failure in the shapes of structure.

\subsubsection{Hammer}

1) After the sheet is drawn out of the press-breaking machine, there may be less bending in the center of the folded/bended sheet.

2) The less bended sheet is then hammered to make it equally bended as the two ends of the sheet.

\subsubsection{Welding Machine}

1) After the two parts of a structure of the innovative Ishapes is formed, it is then jointed by spot welding.

2) It should be very minute so that it does not interfere with the strength of the shapes.

\subsection{Specimen Preparation}

The original size of the sheet is $1200 \mathrm{~mm} \times 1800 \mathrm{~mm}$. The cold-formed sheets are cut to the required measurements in according to the desired shapes.

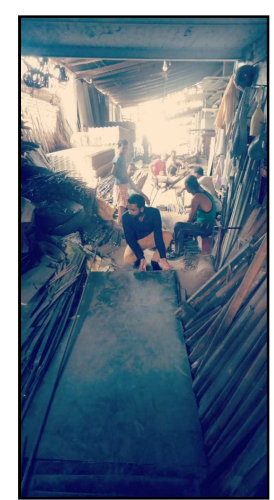

Figure 1. Selection of cold form steel sheet on site.

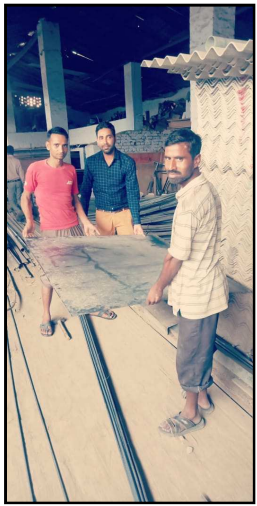

Figure 2. Placing of sheet on ground.

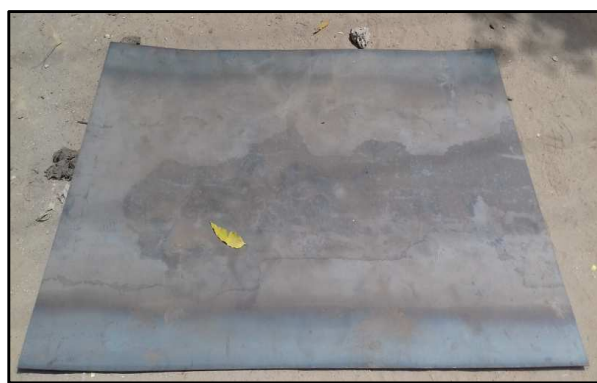

Figure 3. Raw plain cold formed steel sheet.

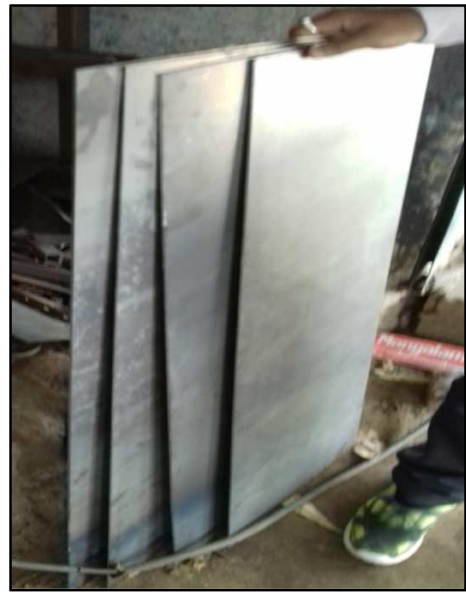

Figure 4. Measurement of steel sheet.

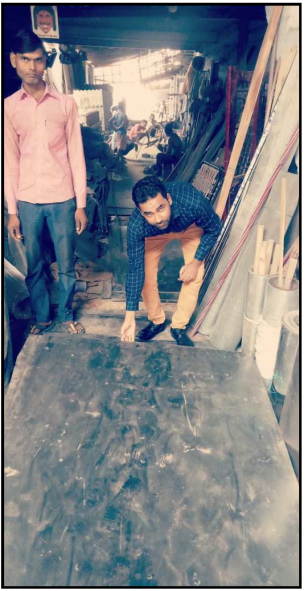

Figure 5. Preparations for folding.

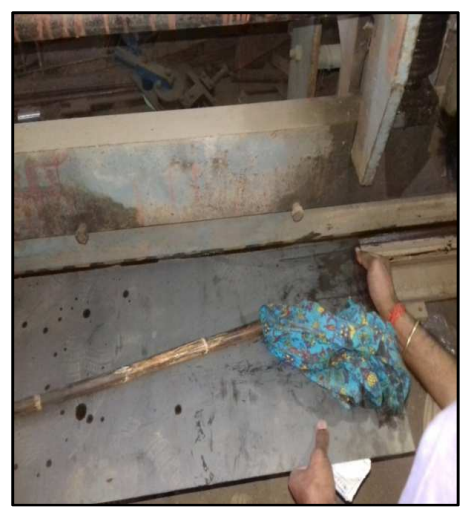

Figure 6. Molding in Pressing machine. 


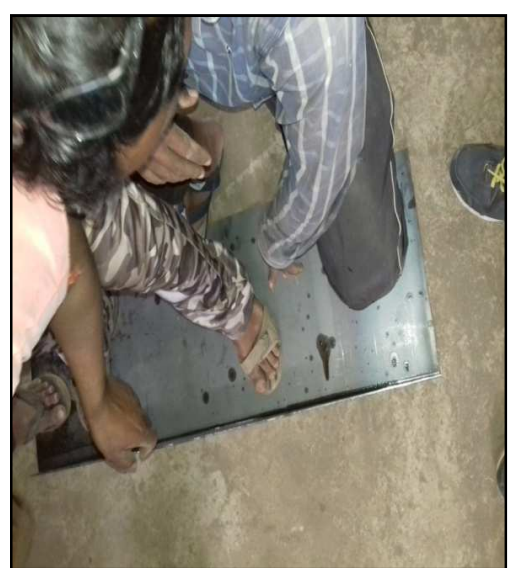

Figure 7. Hammering.

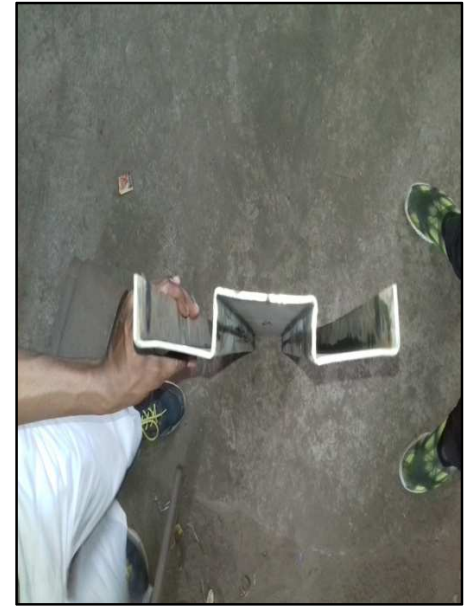

Figure 8. Half prepared structure.

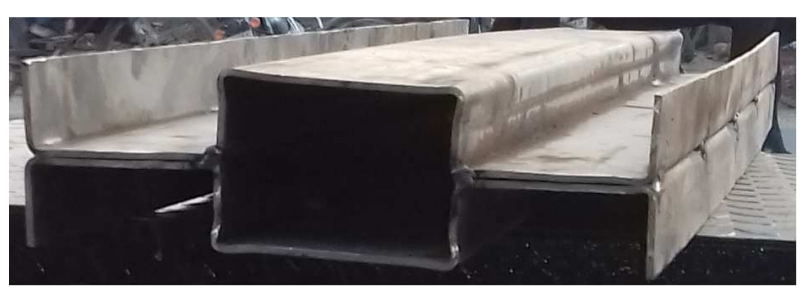

Figure 9. Fully manufactured structure.

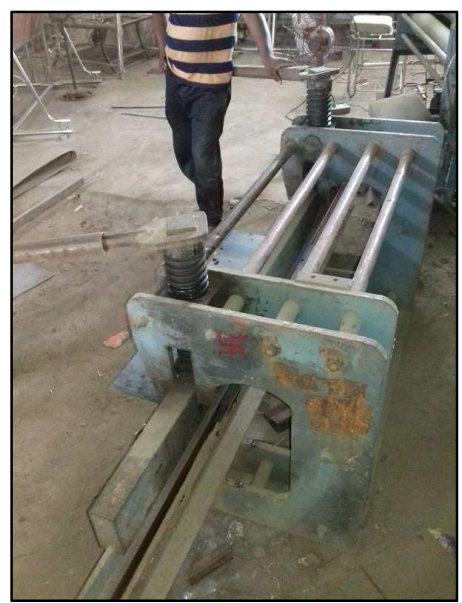

Figure 10. Pressing Machine.

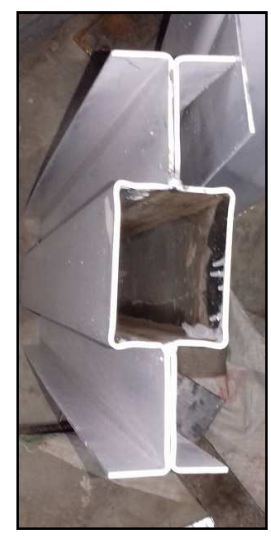

Figure 11. Rectangular I-shaped section.

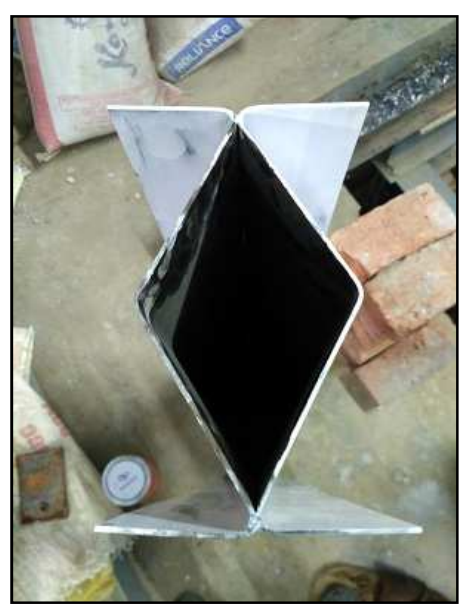

Figure 12. Parallelogram I-shaped.

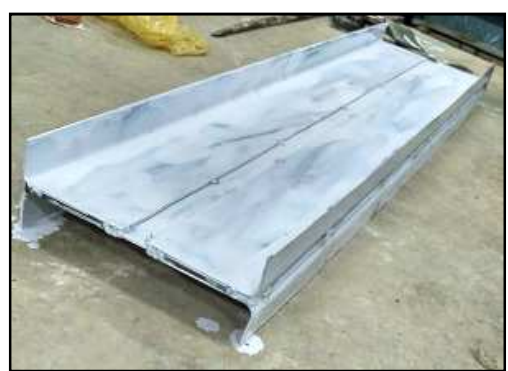

Figure 13. Innovative I-section.

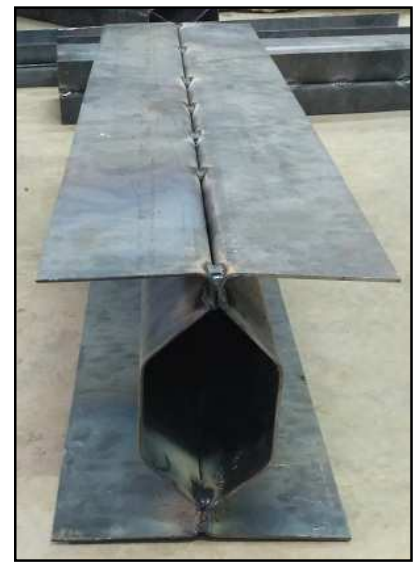

Figure 14. Hexagonal I-shapes. 


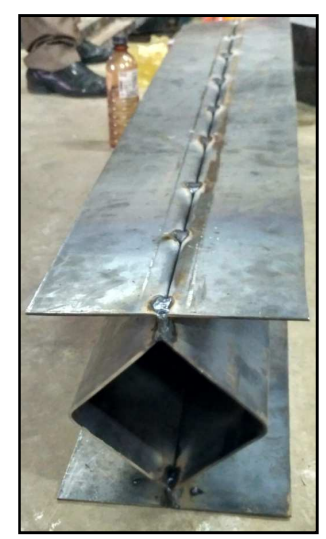

Figure 15. Rhombus I-shaped.

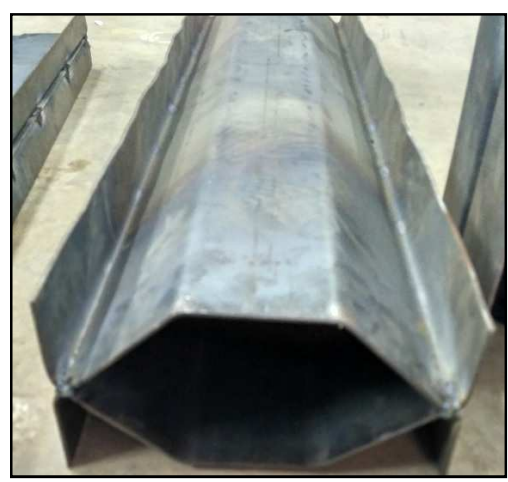

Figure 16. Hexagonal I-shaped.

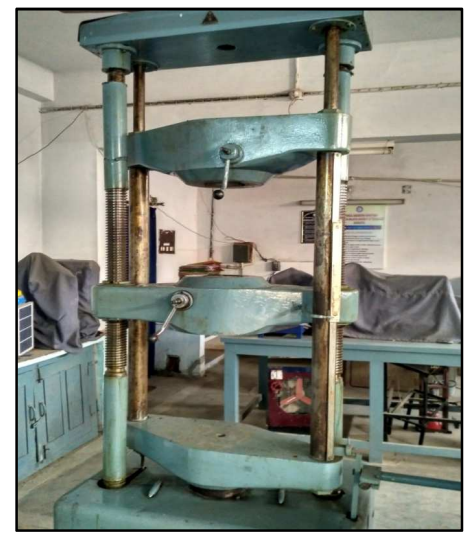

Figure 17. The Universal testing machine.

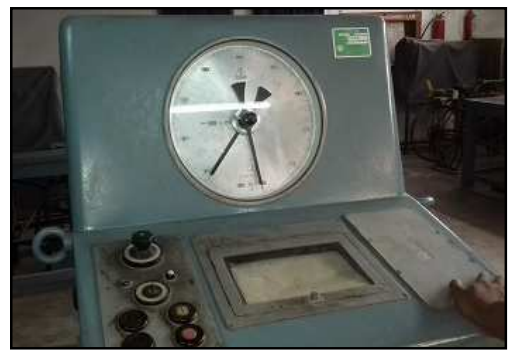

Figure 18. U. T. M. Data Recording System.

1) For the calculation of the load bearing capacity of the different innovative I-shape structures, they are tested on the U. T. M.

2) The shape of the different structures is deformed under
UTM but at different loads.

3) This different deformation of the structures gives us the clear view that the structures are having different strength.

4) Thus, the different strength gives us the desired idea/result that different shapes have different load bearing capacity.

\section{Experimental Result}

Experimental results obtained based on the maximum load carrying capacity and Load - deflection value of different Innovative I- section.

\subsection{Load - Deflection Relationships}

\subsection{Load - Deflection Relationship for Rectangular I-SECTION}

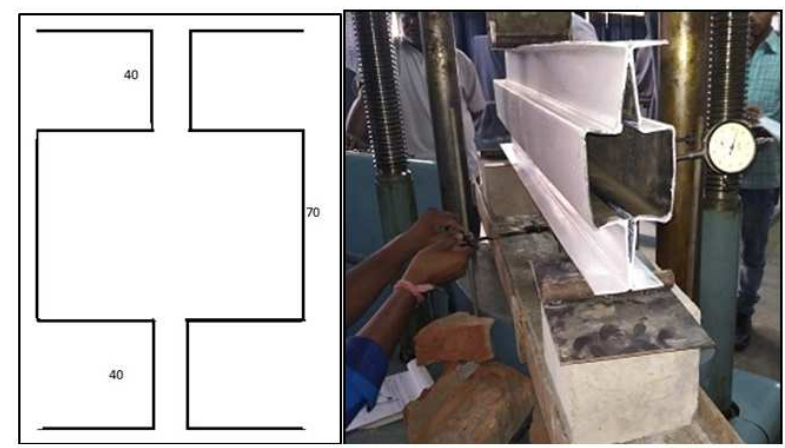

Figure 19. Failure shape of Rectangular I- section.

Table 1. Load-deflection value for Rectangular I- section.

\begin{tabular}{lll}
\hline S. No. & LOAD $(\mathbf{K N})$ & DEFLECTION $(\mathbf{m m})$ \\
\hline 1. & 0 & 0 \\
2. & 5 & 0.01 \\
3. & 10 & 0.70 \\
4. & 15 & 0.75 \\
5. & 20 & 0.85 \\
6. & 25 & 0.95 \\
7. & 30 & 1.20 \\
8. & 35 & 1.55 \\
9. & 40 & 2.20 \\
10. & 45 & 2.80 \\
11. & 50 & 3.60 \\
12. & 52.5 & 4.50 \\
\hline
\end{tabular}

Load- Deflection curve for Rectangular Isection

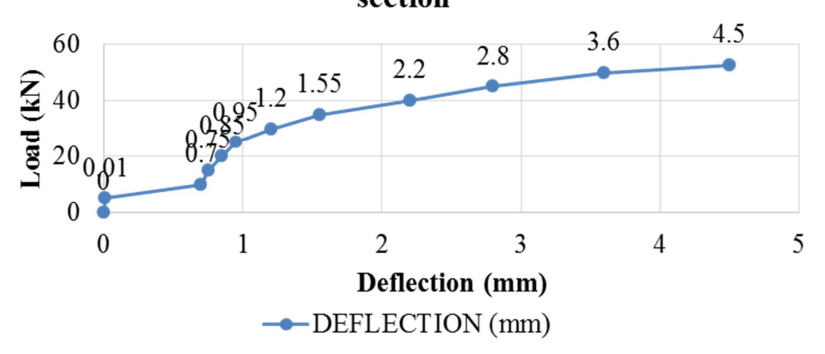

Figure 20. Graph for Load - deflection curve of Rectangular I- section. 


\subsubsection{Load - Deflection Relationship for Hexagonal I-SECTION}

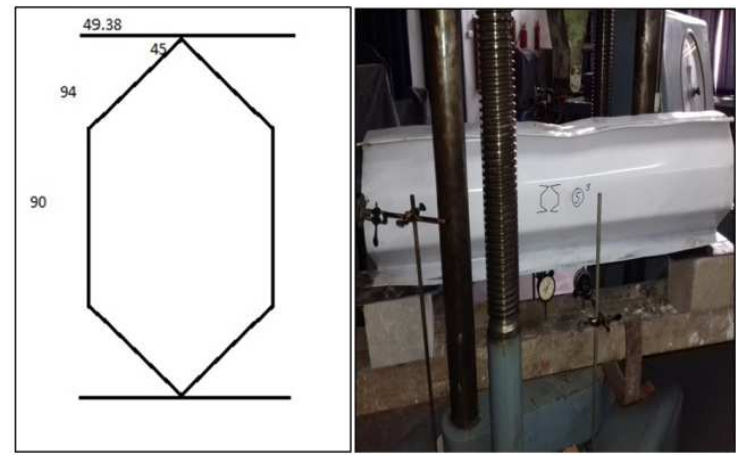

Figure 21. Failure shape of Hexagonal I- section.

Table 2. Load-deflection values for Hexagonal I- section.

\begin{tabular}{lll}
\hline S. No. & LOAD $(\mathbf{K N})$ & DEFLECTION $(\mathbf{m m})$ \\
\hline 1. & 0 & 0 \\
2. & 5 & 1.70 \\
3. & 10 & 2.00 \\
4. & 15 & 2.30 \\
5. & 20 & 2.70 \\
6. & 25 & 3.10 \\
7. & 30 & 3.80 \\
8. & 35 & 4.60 \\
9. & 40 & 5.80 \\
\hline
\end{tabular}

Load- Deflection curve for Hexagonal I-section

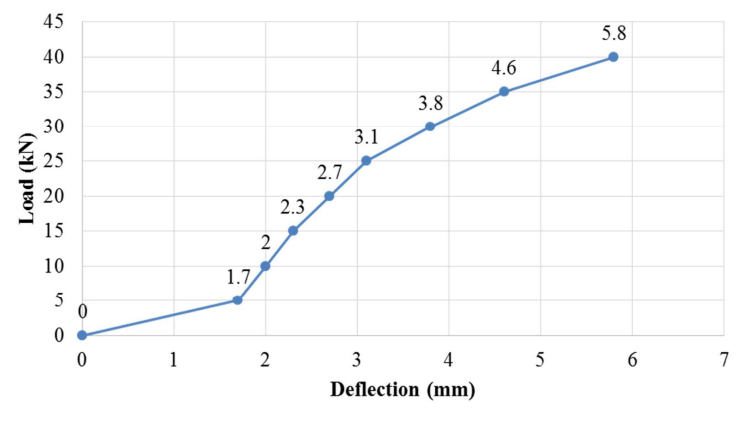

$\rightarrow$ DEFLECTION $(\mathrm{mm})$

Figure 22. Graph for Load - deflection curve of Hexagonal I- section.

\subsubsection{Load - Deflection Relationship for Webbed Hexagonal I-SECTION}

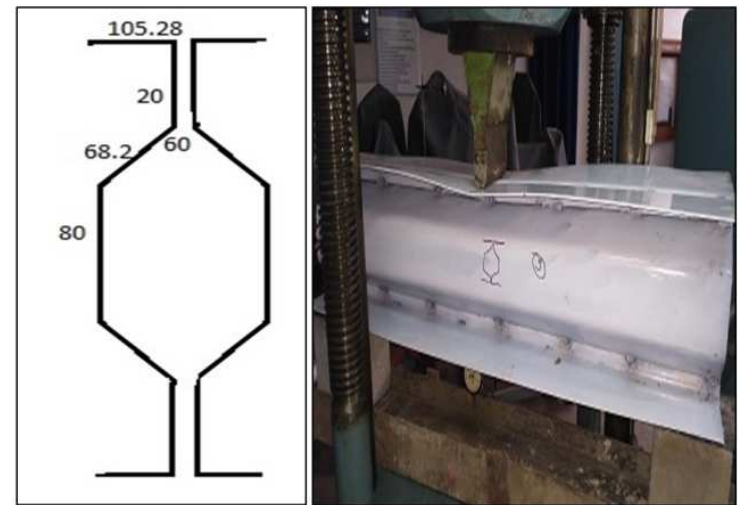

Figure 23. Failure shape of Webbed Hexagonal I- section.
Table 3. Load - deflection values for Webbed Hexagonal I- section.

\begin{tabular}{lll}
\hline S. No. & LOAD $(\mathbf{K N})$ & DEFLECTION $(\mathbf{m m})$ \\
\hline 1. & 0 & 0 \\
2. & 5 & 0.80 \\
3. & 10 & 1.40 \\
4. & 15 & 1.90 \\
5. & 20 & 2.30 \\
6. & 25 & 2.90 \\
7. & 30 & 3.30 \\
8. & 35 & 4.10 \\
9. & 36 & 4.90 \\
\hline
\end{tabular}

Load- Deflection curve for webbed hexagonal I-section

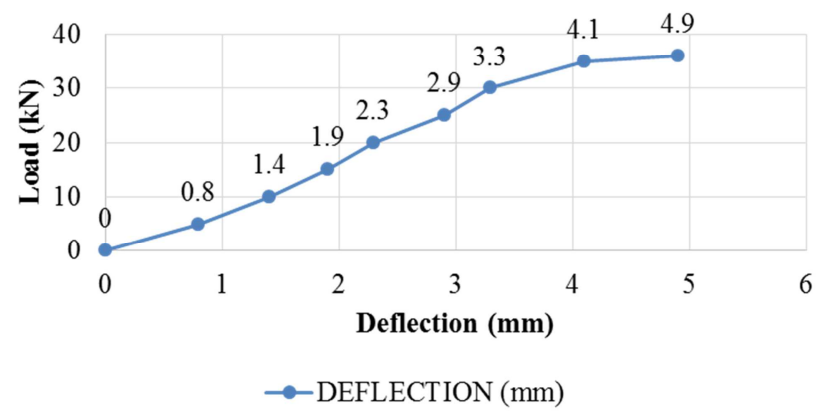

Figure 24. Graph for Load - deflection curve of Webbed Hexagonal Isection.

\subsubsection{Load - Deflection Relationship for Webbed Rectangular I-SECTION}

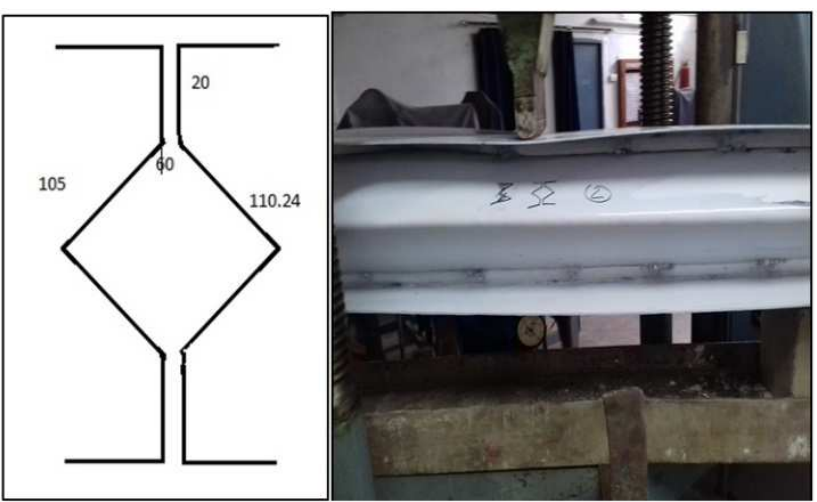

Figure 25. Failure shape of Webbed Rectangular I- section.

Table 4. Load - deflection values for Webbed Rectangular I- section.

\begin{tabular}{lll}
\hline S. No. & LOAD $(\mathbf{K N})$ & DEFLECTION $(\mathbf{m m})$ \\
\hline 1. & 0 & 0 \\
2. & 5 & 0.50 \\
3. & 10 & 1.20 \\
4. & 15 & 1.80 \\
5. & 20 & 2.20 \\
6. & 25 & 2.70 \\
7. & 30 & 3.40 \\
8. & 31 & 4.30 \\
\hline
\end{tabular}




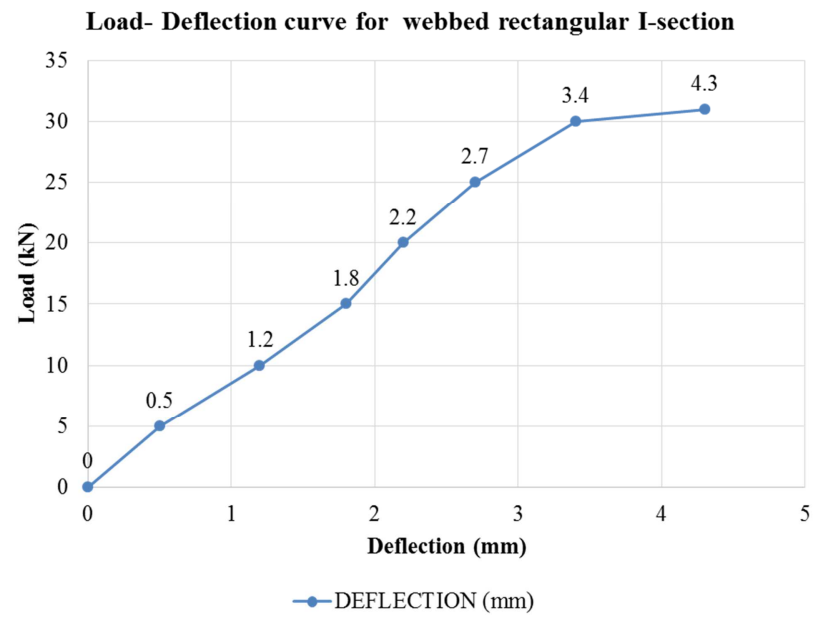

Figure 26. Graph for Load - deflection curve of Webbed Rectangular Isection.

\subsubsection{Load - Deflection Relationship for Innovative I-SECTION}

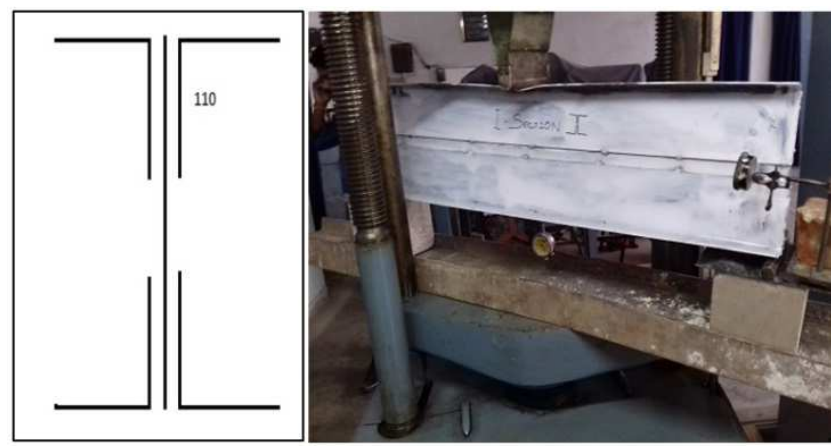

Figure 27. Failure shape of Innovative I- section

Table 5. Load - deflection values for Webbed Rectangular I- section.

\begin{tabular}{lll}
\hline S. No. & LOAD $(\mathbf{K N})$ & DEFLECTION $(\mathbf{m m})$ \\
\hline 1. & 0 & 0 \\
2. & 5 & 0.40 \\
3. & 10 & 0.70 \\
4. & 15 & 0.90 \\
5. & 20 & 1.20 \\
6. & 25 & 1.45 \\
7. & 30 & 1.85 \\
8. & 35 & 2.20 \\
9. & 40 & 2.45 \\
10. & 45 & 2.85 \\
11. & 50 & 3.10 \\
12. & 55 & 3.30 \\
13. & 60 & 3.45 \\
14. & 65 & 3.75 \\
15. & 70 & 3.90 \\
16. & 72 & 4.10 \\
\hline
\end{tabular}

Load- Deflection curve for innovative I-section

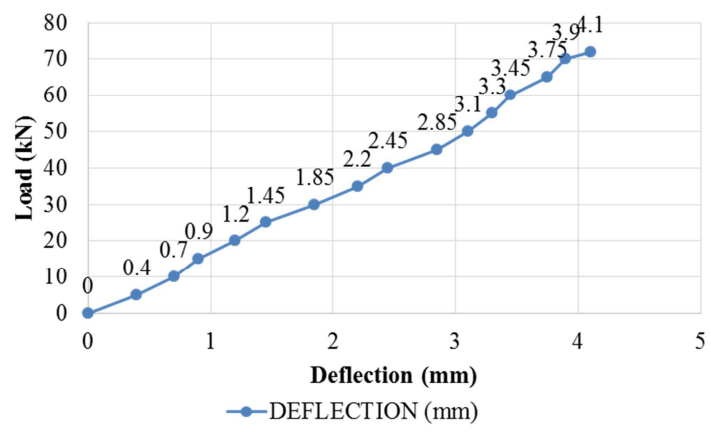

Figure 28. Graph for Load - deflection curve of Innovative I- section

\subsubsection{Load - Deflection Relationship for Diamond Shaped I-SECTION}

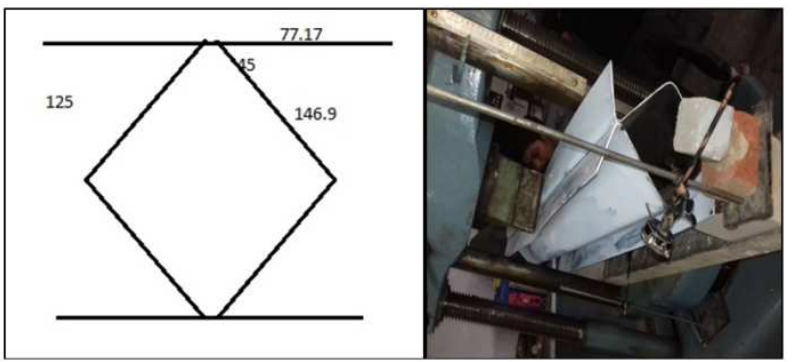

Figure 29. Failure shape of Diamond shaped I-section.

Table 6. Load - deflection value for Diamond shaped I- section.

\begin{tabular}{lll}
\hline S. No. & LOAD $($ KN) & DEFLECTION $(\mathbf{m m})$ \\
\hline 1. & 0 & 0 \\
2. & 5 & 0.45 \\
3. & 10 & 1.10 \\
4. & 15 & 1.40 \\
5. & 20 & 2.00 \\
6. & 25 & 2.20 \\
7. & 30 & 2.80 \\
8. & 35 & 3.10 \\
9. & 36 & 3.45 \\
\hline
\end{tabular}

Load- Deflection curve for diamond-shaped Isection

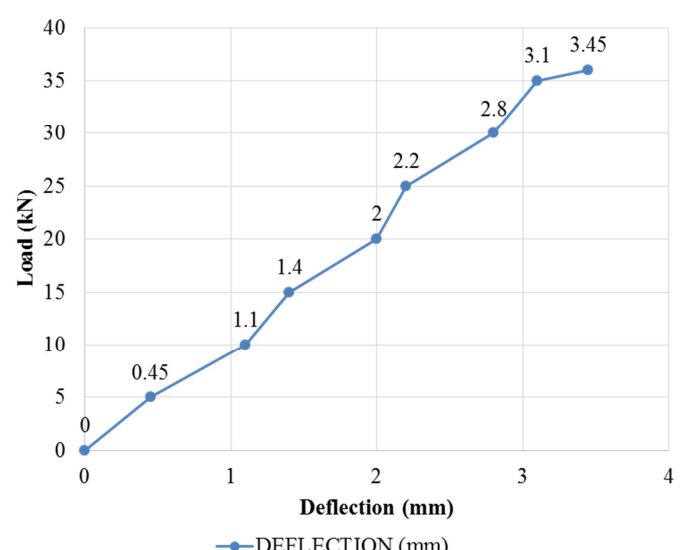

$\rightarrow$ DEFLECTION $(\mathrm{mm})$

Figure 30. Graph for Load - deflection curve of Diamond shaped I- section. 


\section{Maximum Load Carrying Capacity}

Table 7. Maximum Load Carrying Capacity for Different Innovative Isection.

\begin{tabular}{lll}
\hline S. NO. & SECTION NAME & $\begin{array}{l}\text { Maximum Load Carrying } \\
\text { Capacity }(\mathbf{K N})\end{array}$ \\
\hline 1 & Rectangular I- section & 52.50 \\
2 & Hexagonal I- section & 40 \\
3 & Webbed Hexagonal & 36 \\
4 & Webbed rectangular & 31 \\
5 & Innovative I- section & 72 \\
6 & Diamond shaped & 36 \\
\hline
\end{tabular}

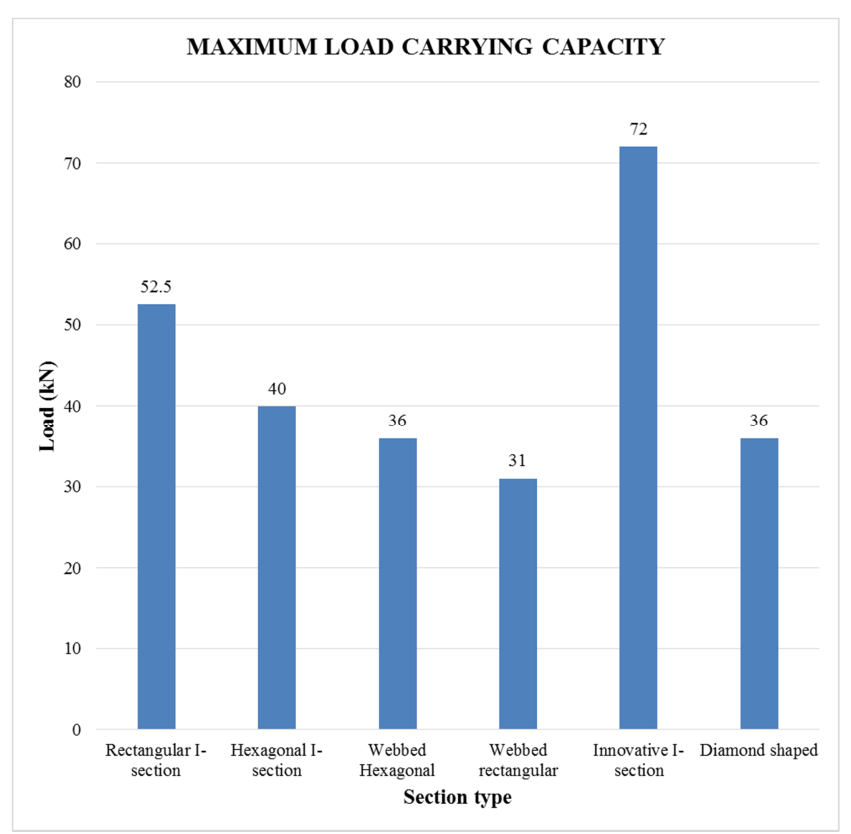

Figure 31. Graph for maximum load carrying capacity of different innovative I- section.

\section{Conclusion}

Cold form steel sections were tested on a UTM with concentrated load to determine the load carrying capacity and the failure patterns for different cold form beam sections with using of spot welded connection. The boundary conditions provided was roller at both ends. The theoretical load carrying capacity of hot-rolled steel section ISMB $100 @ 87.22 \mathrm{~N} / \mathrm{m}$ was $50.29 \mathrm{kN}$. The experimental load carrying capacity for Rectangular I-section under flexure was $52.5 \mathrm{kN}$. The experimental load carrying capacity for Hexagonal I-section under flexure was $40 \mathrm{kN}$. The experimental load carrying capacity for webbed hexagonal Isection under flexure was $36 \mathrm{kN}$. The experimental load carrying capacity for webbed rhombus I-section under flexure was $31 \mathrm{kN}$. The experimental load carrying capacity for diamond-shaped I-section under flexure was $36 \mathrm{kN}$. The experimental load carrying capacity for innovative I-section under flexure was $72 \mathrm{kN}$. From experimental investigation, the Maximum load carrying capacity among different innovative I shaped cold form steel beam sections was found innovative I-section 1 with load carrying capacity of $72 \mathrm{kN}$ having maximum deflection of $4.10 \mathrm{~mm}$.

\section{Future Scope}

1. Analysis and Design of Cold Formed Steel done for multi-story building by considering various sectional properties of cold formed steel. Also design different parts such as eave strut, bracing system, sag rod and foundation can be done for different consideration of section.

2. The self-shape optimization principle will be extended in the future to incorporate the moment capacity in a similar manner to the axial capacity.

3. The final aim of this study is to optimize cross-sections for practical industrial uses, and the limitations of coldforming processes will be added to the algorithm.

4. In addition to the manufacturing constraints, construction constraints specific to various types of cold-formed steel applications, such as purlins or girts, will be also added to the algorithm.

5. As discussed, the algorithm optimizes for distortional and global buckling, and the buckling mode interaction will need to be considered in the optimization process.

\section{Acknowledgements}

This research was supported by the Department of Civil Engineering of Rajshree Institute of Engineering \& Technology, Rithora, Bareilly, and the Department of Civil Engineering, Future Institute of Engineering \& Technology, Faridpur, Bareilly, Uttar Pradesh, India. We thank our colleagues from Rajshree Institute of Engineering \& Technology, Rithora, Bareilly who provided insight and expertise that greatly assisted the research, although they may not agree with all of the interpretations and conclusions of this paper.

We thankful to [Mr. Bhoopendra Singh, Head of Civil Engineering Department, Future Institute of Engineering \& Technology, Faridpur, Bareilly, and Uttar Pradesh] for assistance with this Research paper.

We would also like to show our gratitude to the Following Persons for sharing their pearls of wisdom with us during the course of this research.

1. Mr. Bhoopendra Singh, Head of Civil Engineering Department at Future Institute of Engineering \& Technology, Faridpur, Bareilly, Uttar Pradesh, India.

2. Mr. Saurabh Prakash Dixit, Assistant Professor, Civil Engineering Department at Future Institute of Engineering \& Technology, Faridpur, Bareilly, Uttar Pradesh, India.

3. Mr. Gaurav Singh, PhD Research Scholar, Civil Engineering Department at Madan Mohan Malaviya University of Technology, Gorakhpur, Uttar Pradesh, India.

4. Mr. Saurabh Singh, P. G. Research Scholar, Civil Engineering Department at Madan Mohan Malaviya University of Technology, Gorakhpur, Uttar Pradesh, India. 


\section{References}

[1] AISI S100 (2012) North American Specification for the Design of Cold-Formed Steel Structural Members. 2012 Edition American Iron and Steel Institute, Washington, USA.

[2] Winter G, Pian RHJ (1946) Crushing Strength of Thin Steel Webs. Engineering Experiment Station Cornell University Ithaca NY.

[3] Zetlin L (1955) Elastic instability of flat plates subjected to partial edge loads. Journal of the Structural Division.

[4] Hetrakul N, Yu WW (1978) Structural Behaviour of Beam Webs subjected to Web Crippling and a combination of Web crippling and bending. Civil engineering study University of Missouri-Rolla, USA.

[5] Yu WW (1981) Web Crippling and Combined Web Crippling and Bending of Steel Decks. Civil Engineering Study 81-2, University of Missouri-Rolla, Rolla, MO.

[6] Santaputra C (1986) Web crippling of high strength of coldformed steel beams. University of Missouri-Rolla, USA.

[7] Santaputra C, Parks MB, Yu WW (1989) Web-crippling strength of cold formed steel beams. J StructEng 115: 25112527 .

[8] Bhakta BH, LaBoube RA, Yu WW (1992) The Effect of Flange Restraint on Web Crippling Strength. Final Report, Civil Engineering Study 92-1, University of Missouri-Rolla, Rolla, MO.

[9] Wing BA (1981) Web crippling and interaction of bending and web crippling of unreinforced multi-web cold-formed steel sections. University of Waterloo, Waterloo Canada.

[10] Wing BA, Schuster RM (1982) Web crippling of decks subjected to two flange loading. Proceeding of the 6yh International Specialty Conference on Cold Formed Steel Structures, University of Missouri-Rolla, Rolla, MO.

[11] Parabakaran K (1993) Web Crippling of Cold Formed Steel Sections. Department of Civil Engineering, University of Waterloo, Canada.

[12] Beshara B, Schuster RM (2000) Web Crippling Data and Calibrations of Cold Formed Steel Members. Research Report, RP00-2, American Iron and Steel Institute, Washington, USA.

[13] Young B, Hancock GJ (1998) Web Crippling Behavior of Cold-Formed Unlipped Channels. Proceedings of the 14th International specialty conference on Cold Formed Steel Structures, University of Missouri Rolla, USA.

[14] Prabakaran K, Schuster PM (1998) Web crippling of coldformed steel members. Proceedings of the 14th International Specialty Conference on Coldformed Steel Structures, S1. Louis, University of Missouri-Rolla, MO.

[15] Beshara B (1999) Web crippling of cold-formed steel members. University of Waterloo, Waterloo, Canada.

[16] Schafer BW, Pekoz T (1998) Direct strength prediction of cold-formed steel members using numerical elastic buckling solutions. 14th International Specialty Conference on ColdFormed Steel Structures, St., Louis, MO.

[17] Choy MY, Jia XF, Yuan X, Zhou J, Wang HS, et al. (2014) Direct Strength Method for Web Crippling of Cold-Formed Steel C- and Z- Sections Subjected to Two-Flange Loading. Proceedings of Annual Stability Conference, Structural Stability Research Council, Toronto, Canada.

[18] Langan JE, Yu WW (1994) Structural Behaviour of Perforated web elements of Cold-Formed Steel Flexural Members Subjected to Web crippling and a combination of Web Crippling and Bending. Civil Engineering Study, Missouri University of Science and Technology, USA.

[19] Dutta, B. N. "Estimate \& Costing in Civil Engineering."

[20] Jain, A. K., "Reinforced Concrete, Limit State design."

[21] Punamia, B C., Jain, A., Jain, A. K. "RCC Designs (Reinforced Concrete Structure)".

[22] Varghese, P. C, "Design of Reinforced Concrete Structure."

\section{Biography}

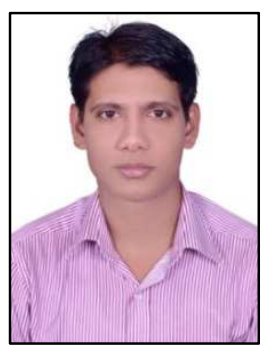

Lokendra Kaushal is currently working as an Assistant Professor in Department of Civil Engineering at Future Institute of Engineering \& Technology, Faridpur, Bareilly, Uttar Pradesh, India.

He have been Completed his P. G. Degree M. Tech (Structural Engineering) in 2017 from Madan Mohan Malaviya University of Technology, Gorakhpur, Uttar Pradesh, India. He have been Completed his Bachelor Degree B. Tech (Civil Engineering) in 2013 from Dr. A. P. J. Abdul Kalam Technical University, Lucknow, Uttar Pradesh, India.

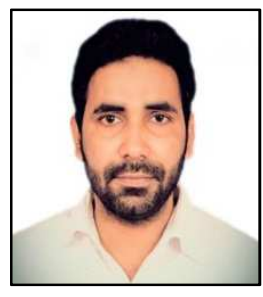

Mohd Rashid is currently a P. G. Research Scholar in the Department of Civil Engineering at Rajshree Institute of Engineering \& Technology, Rithora, Bareilly, Uttar Pradesh, India.

He have been Completed his Bachelor Degree B. Tech (Civil Engineering) in 2014 from Dr. A. P. J. Abdul Kalam Technical University, Lucknow, Uttar Pradesh, India. 